Original Research Paper

\title{
Implementation of Health Information System-A Case Study of Magrabi Hospitals, KSA
}

\author{
${ }^{1,2}$ Diaa Eldin ELSaied and ${ }^{3}$ Habib Ullah Khan \\ ${ }^{I}$ Department of Computer Science, University of Liverpool, UK \\ ${ }^{2}$ Magrabi Hospitals and Centers, Jeddah, Saudi Arabia \\ ${ }^{3}$ Department of Accounting and Information Systems, \\ College of Business and Economics, Qatar University, P.O. Box 2713, Doha, Qatar
}

Article history

Received: 26-02-2017

Revised: 26-04-2017

Accepted: 11-05-2017

Corresponding Author:

Habib Ullah Khan

Department of Accounting and Information Systems, College of Business and Economics, Qatar University, P.O. Box 2713, Doha, Qatar

Email: habib.khan@qu.edu.qa

\begin{abstract}
Today's healthcare market has created its niche by adopting emerging technologies and ensuring minimal rate of failures. Embracing integrated Health Information System (HIS) is one such venture that not only helps the organization to excel in the market but also caters to the needs of the public. The present research paper is a case study of HIS implementation of Magrabi hospitals and centres, in Saudi Arabia. Though implementing HIS is a herculean task, with respect to the efforts as well as investment, Magrabi could achieve this task with at most care. The system could promote service efficacy across all the centres and hospitals of Magrabi. The paper analyses the procedures and strategies followed in order to prepare the entity ready for transformation. That is, the method of actualizing the health system implementation is also detailed in this study. Overall, the case research tried to know the extent of improvement took place in all the streams of operations in Magrabi group after automation. To gather this information, data is collected from all the in-charges of respective departments as well as users, who are in managerial cadre. This data is tabulated against various cycles (revenue and payroll). From the opinion of the stakeholders it can be easily understood that HIS has brought a sea change in the service flows of Magrabi group. Apart from the benefits of HIS implementation, the lacunae of the study along with the future research prospects in these lines are suggested for the possible improvements.
\end{abstract}

Keywords: Health Information System (HIS), Information Technology (IT), Electronic Health Record, Implementation, Saudi Arabia

\section{Introduction}

The influence of information systems on the pace of development in various realms is just amenable. Such a considerable impact on the health and healthcare fields are worth discussing. As the companies of the world are gearing to fine tune their health care services so as to make a niche in the service industry, the review of extent of reach can be considered as a yardstick. So, a thorough understanding of the impact and the advantages that are gained due to implementation of the health information system is very much necessary to establish a patient centric service system in any health entity. This is the main reason for the health care world's run behind the health information systems, ubiquitously. There are different types of information systems (like transaction processing systems, management information systems, decision support systems and expert systems) and depending on the nature of the organizations, a particular type of system is opted and applied.

The general understanding about the Health Information System (HIS) can reveal it as an amalgamation of software, hardware, people and processes to cater to a range of services in a healthcare entity so as to ensure the collaborative work aimed to achieve the goals of the organization (Al-Gharbi et al., 2015; Silver et al., 1995; Khan, 2013a; Awan et al., 2012; Najmi et al., 2015; Heang and Khan, 2015; Ho et al., 2016; Smuts et al., 2017; Bashir and Khan, 2016). The active players in the working group would be the stake holders of the hospital belonging to a range of departments and centres. Along with growing technology, many health information systems are being tailored as per the need of the organization. This need is 
basically decided by the size of the hospital, type of the hospital (clinic or hospital), number of beds as well as the assortment of services offered to the patients. So, these particulars decide the type of HIS to be implanted and hence the cost.

In spite of the mushrooming HIS throughout the world, only some countries prefer the readymade modules, while the other are venturing to develop a nationwide health information system and Saudi Arabia is one among the latter. Since1925, in which year Health Department and a Bureau of Health and Aid are initiated in Saudi Arabia to improve reach and quality of healthcare services, the rulers have been taking vital strides to establish a sophisticated HIS in the country to cater to the needs of the people (Al-Sharqi and Abdullah, 2013; Bankole et al., 2017). However, because of the infrastructural, cultural and regional barriers, the information systems are not instituted to the full extent (Khalifa, 2014; Halabi et al., 2014; Hassan et al., 2016; Khan and Fournier-Bonilla, 2016; Khan et al., 2016). Even today, there are many lacunae that are persisting in the healthcare field, which are hindering the smooth flow of operations (Hasanain et al., 2015; Khan and Uwemi, 2017). Nevertheless, renowned health care centres in the country are trying to grab the slice of the pie in the healthcare market by deploying timely strategies so that the services are delivered to the needy in an integrated manner. Magrabi Hospitals and Centres is one such healthcare player, which recently established health information system throughout its centres and pioneering to excel in the service industry. Through these new ventures, the organization aims to achieve the goal of its own and hence the country's.

In order to achieve this, Magrabi Hospitals and Centres deployed implementation of HIS across all its Hospitals and Centres. This initiative has synchronized all its operations and strengthened the service chains with seamless flows. This task is actualized by coordinating with various departments and the stake holders as well as investing huge amount in this regard. Though, this kind of venture in Saudi Arabian health setting is an adventurous task, Magrabi group could overcome the hurdles by constant endeavour and by conducting many trials before the full range of implementation. So, the present work intends to study the gamut of the strides taken to achieve this task of successful health system implementation by considering this as a case study. The flow of the work would be discussing the step by step process adopted to actualize the gigantic task to link the group of hospitals and centres spread across Saudi Arabia.

Thus, this research work deploys case study methodology to compare the business processes before and after the system's implementation. Previous research works have shown that such implementation has a positive effect in terms of increasing the efficiency of the processes. So, based on this understanding, a scenario- based case study would be employed with respect to each business area in order to determine the improvements achieved after implementing the fully integrated system. Breaking down each business area into business processes and assessing each process against an industry standard or best practices would enable measurement of the effect of the system utility on each particular business process.

For instance, in HR, the performance of a set of processes right from new hire to the final appraisal would be checked before and after the health information system implementation. Irrespective of the department, the efficacy of the process can be understood with respect to business processes, decision making and various other controls. The study proceeded by literature review which discusses the general process of health system implementation as well as the bottle necks encountered in the process. Also, the issues that came across the implementation process of Magrabi Hospitals and the effects of implementation would be discussed in detail. The observations noted during the study and the opinion of the stake holders about the benefits of HIS implementation would be presented at the end of the study. The contributions of this study can not only reveal the systematic plan that one has to follow to adapt new technology but also cautions about the points to ponder.

\section{Review of Literature}

Health information can be perceived as any piece of information that reveals or aimed at the well-being of the patient. Health information system, being most sought after topic in today's world is subjected to umpteen modifications in the context of contemporary challenges (Al-Sharqi and Abdullah, 2013; Khan and Ejike, 2017). How much ever modifications took place, the end of the strategies is to assure sophisticated and prompt healthcare. With this motto, healthcare entities are striving to realize their goals through rendering their part to the patients either by adopting readymade health systems or designing the system as per the requirements of the organization (Hayajneh and Zaghloul, 2012; Anwar et al., 2011; Khan, 2016; Askoul et al., 2016).

\section{Health Information System-Pros and Cons}

Health information system is defined in a simpler manner as platform that facilitates information sharing across the stake holders in the healthcare vertical. In particular, HIS can be perceived as an integrated system aimed at serving various departments of the healthcare realm such as medical, administrative, financial, legal and patient related (Al-Gharbi et al., 2015; Aziz and Mohamadali, 2015; Khan et al., 2014a; Uwemi and Khan, 2016). Though evolution of health information system is dated back to two decades ago, still there exists 
numerous dilemmas for selection process of a suitable information system for a particular health setup. The apprehension for this selection is owing to many reasons like: The cost of information system, the gap between the requirements for establishing the system and the prevailing conditions of the organisation with respect to resources, the history of failures of HIS for various organisations and the inability of the new system to serve the needs of the stake holders etcetera (Al-Dosari, 2012; Ali, 2013; Musa et al., 2015; Khan and Adediji; 2017). The following Fig. 1 explains the linkages among such streams of hospital operations flow. Also, they explain the linkages between the process cycles as mentioned in Table 1.

\section{Saudi Arabian Healthcare Setting}

The history of Saudi Arabian Healthcare setting can be understood in four phases. Though health consciousness has prevailed in Saudi since a long time, being a prominent place for religious beliefs of Muslim community since decades, a structured healthcare system got established during 1920's. From then, the periods of progress in health sector are earmarked as 1925-41, 1941-51, 1951-81 and 1981present (Al-Sharqi and Abdullah, 2013). It is also declared by World Health Organization in year 2000 that Saudi Healthcare System is ranked 29th among 190 of the global health systems (Abukhader, 2015; Almalki et al., 2011). Though, there has been a remarkable ascent in couple of decades with respect to many important health indicators as well as health infrastructure of the country, the drawbacks like lack of standardization, topographical and geographical limitations, growing health concerns of the people and increasing cost of health services etcetera remind the germane strides to be taken with high priority
(Schalkwijk et al., 2016; Alasmary et al., 2014; Khan et al., 2013; 2017a).

As described by Hayajneh and Zaghloul (2012), the Arab Countries' Hospitals (ACH) are much lagging behind in deploying information technology and hence the penetration of HIS. Researchers have been suggesting the lacunae to address in order to make the country's health care field run on par with that of the contemporary world. However, the deep rooted norms and practices are playing a silent role in reneging the anticipated developments (Clementking and Muhammad, 2013; Khalifa, 2013; Khan 2012). In addition, it is important to expertise in the latest methodologies to adapt the technologies depending on the enterprise setup by going through the success stories of the organizations in that particular domain. Explaining about the health data standards in tertiary hospitals of Saudi Arabia, Alkraiji et al. (2013) shares the utility of theories namely, adoption theory and the perspectives of the economics of standards to know the pulse of the stake holders in the organization in adapting themselves to emerging technologies.

Furthermore, to anticipate integrated health system development, many sectors need to be strengthened on par with the upgraded levels. For instance, considering the education sector, research affirms that the country's education system is unable to cater to the needs of the market, in particular healthcare market (Clementking and Muhammad, 2013; Khan, 2013b; Khan et al., 2014b). Having these kind of bottle necks as background, it is a hard task to adopt a sophisticated HIS. However, some organisations are able to achieve this with diligent planning and welldesigned approach. Magrabi Hospitals and centres is one among them.

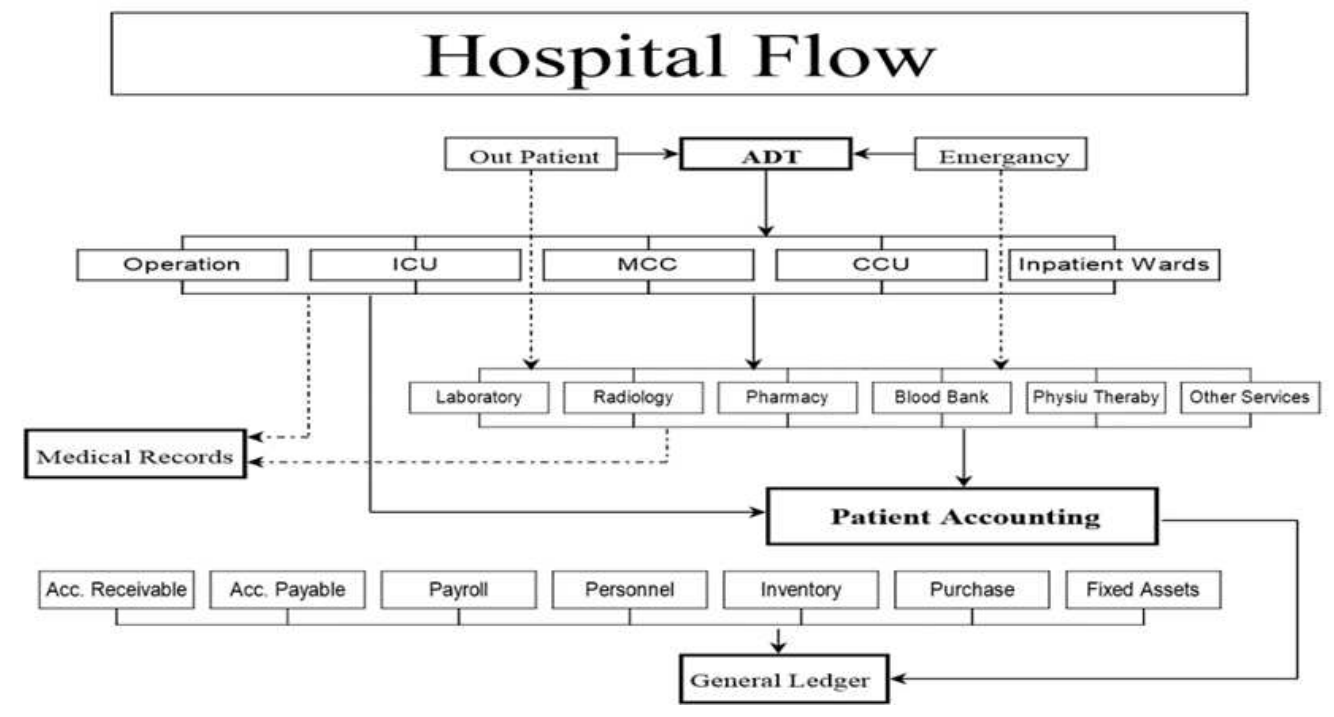

Fig. 1. Typical hospital flow Diagra 


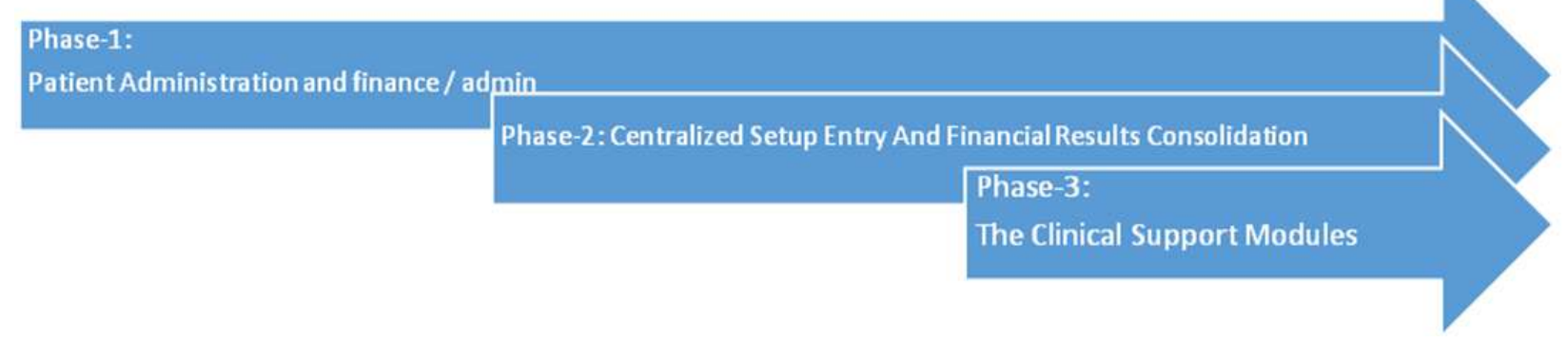

Fig. 2. Phases in the process of HIS implementation

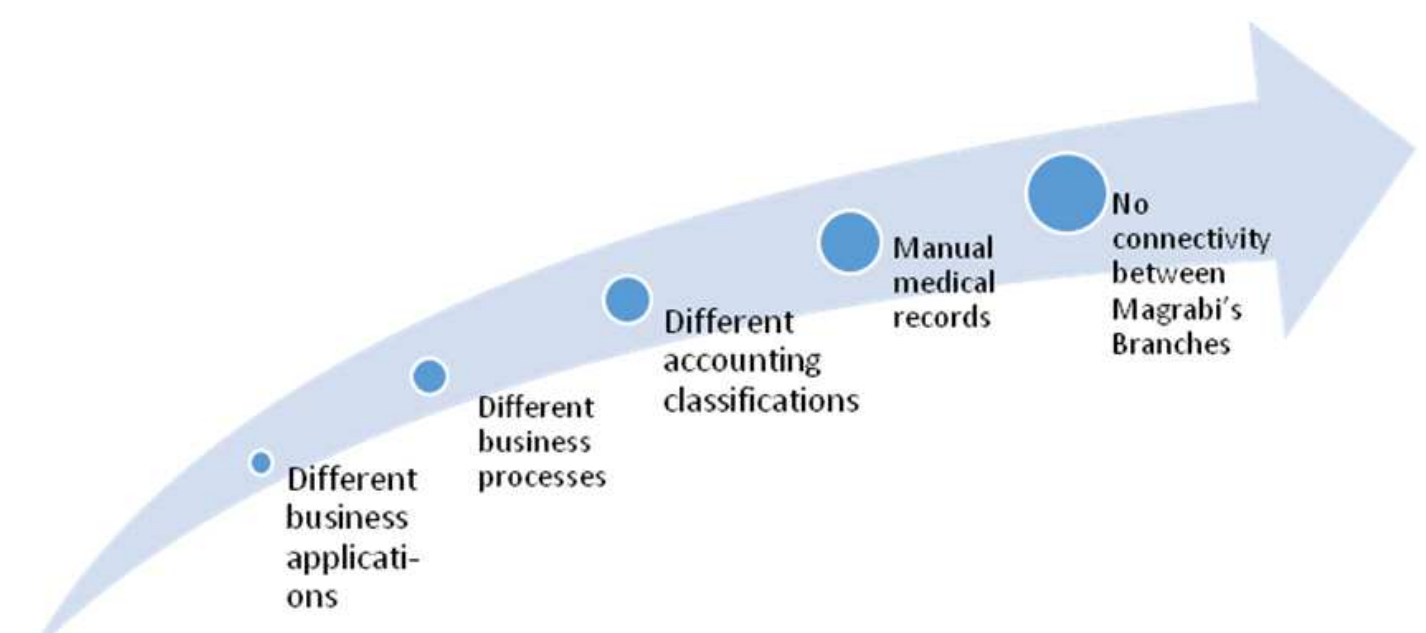

Fig. 3. List of problems led to HIS implementation by Magrabi group

\section{Case Study of Magrabi Hospitals and Centres}

Magrabi Hospitals and Centres is the first and the most well-known, specialised group of hospitals and centres in the Middle East. Founded in 1955, serving $1,000,000$ patients and performing 100,000 surgeries every year. Magrabi Hospitals and Centres has 27 branches. As branches are spread all over the country, establishing a thorough connectivity and integrating all the types of health systems across the branches has become dire necessity for the company. By keeping the past failures of information system implementation in Saudi Arabia, the Magrabi organised many trails before the enterprise implementation. To achieve this task, the consortium happened to invest huge amount (around 20 million SAR). The methodology adopted for implementation in various departments and the version of the managers in that concerned department would be discussed in the coming sections of this paper. However, for the Magrabi group, the general implementation plans carried out by integrating all the processes among the individual units is done in three phases that are given in the Fig. 2.
Prior to implementation, there used to be chaos because of the individual information from each of the centres. As a result of this bits and pieces of information with respect to patients as well as the processes, unexpected delays used to occur in the service delivery chain. In addition to the general problems, the problems raised in the process of information sharing compelled to integrate the information systems. The major blockages encountered in this process can be listed as (i) different business applications (ii) different business processes (iii) different accounting classifications (iv) Manual medical records and (v) No connectivity between Magrabi's branches. They are given in the following Fig. 3.

To address the above mentioned hurdles and to facilitate information system integration, the management of Magrabi happened to adapt the changes that occurred as a precursor for the implementation. They are - (i) the shift in the market from cash based to credit based. Thus, the market changed from $100 \%$ cash patients and gradually increasing towards the credit. This entails the use of 
information systems to enable the organisation to secure the contracted prices and rules, as well as to monitor balances and collections; (ii) the mandate for digitalizing all the services. That is, it became imperative to embrace an electronic health record system so as to reduce the patients' waiting time and to increase the quality of the services provided; (iii) the change of ownership from single to partnership. For the sake of better understanding and managing the processes, all the functions are regrouped under three heads-patient administration, clinical support and finance/administration. Thus the basic functional domains studied across various branches and segregated under the three heads are given in Fig. 4.

A thorough integration of these modules is done in order to reduce the redundancy of information entry, archiving as well as retrieving. As it is mentioned by Fichman et al. (2011), the information systems deployed not only reduced the cost of operations that are performed in various departments but also reduced medical errors. In addition, by embracing the integrated systems, Magrabi could achieve least percentage of transactions errors as well as datasharing errors (Alshami et al., 2014; Grönevall and Danilovic, 2014; Brock and Khan, 2017). There are various adjustments made in the organization to facilitate the changes required as a part of implementation of HIS (Hung et al., 2014). They areincreasing the feasibility of the organization to accommodate the change, enriching the resources so as to modify as per the changing business processes and the vital aspect is the reinforcement of the top management to bolster the multi-faceted transition. Performing these tasks has become a big challenge to Magrabi, as aligning the compulsory alterations with the company's objectives and strategies and reengineering the process flows seamlessly is a herculean task (Abraham and Junglas, 2011; Khan et al., 2017b). Though many market partners are adapting the information systems developed by the vendors, Magrabi took pertinent actions by developing own standard operating procedures for ensuring a continuous support for the new systems throughout (Melin and Axelsson, 2014; Das and Khan, 2016; Awan and Khan, 2016). In spite of the odds that can accrue losses for developing organisation based HIS (Khan et al., 2017b) management put all efforts meticulously by framing apt strategies. As a result they could develop a system that costed less compared to the tailored one along with its maintenance.

In addition, by developing strategies that are associated with the necessary changes of 'to be systems' with more connectivity and reach, Magrabi could hedge against the situations that occurred in the case of implementation in hospitals by Saudi Arabic government (Almalki et al., 2011; Khan and Awan, 2017; Khan and Alhusseini, 2015; Hassan et al., 2015; Bashir et al., 2016; Omonaiye et al., 2015). This case study showcases the advantages of technology up gradation in private health care industry by collecting the feedback from the users through face-to-face interviews as well as personal interviews with top management (Awan et al., 2016; Ejike et al., 2016; Uwemi et al., 2016). To have a better understanding about the total service delivery process, induvial processes are considered and their flow diagrams are prepared for clarity of thought. For instance, the general flow processes for outpatient consultation and patient revisit are given below in Fig. 5 and 6.

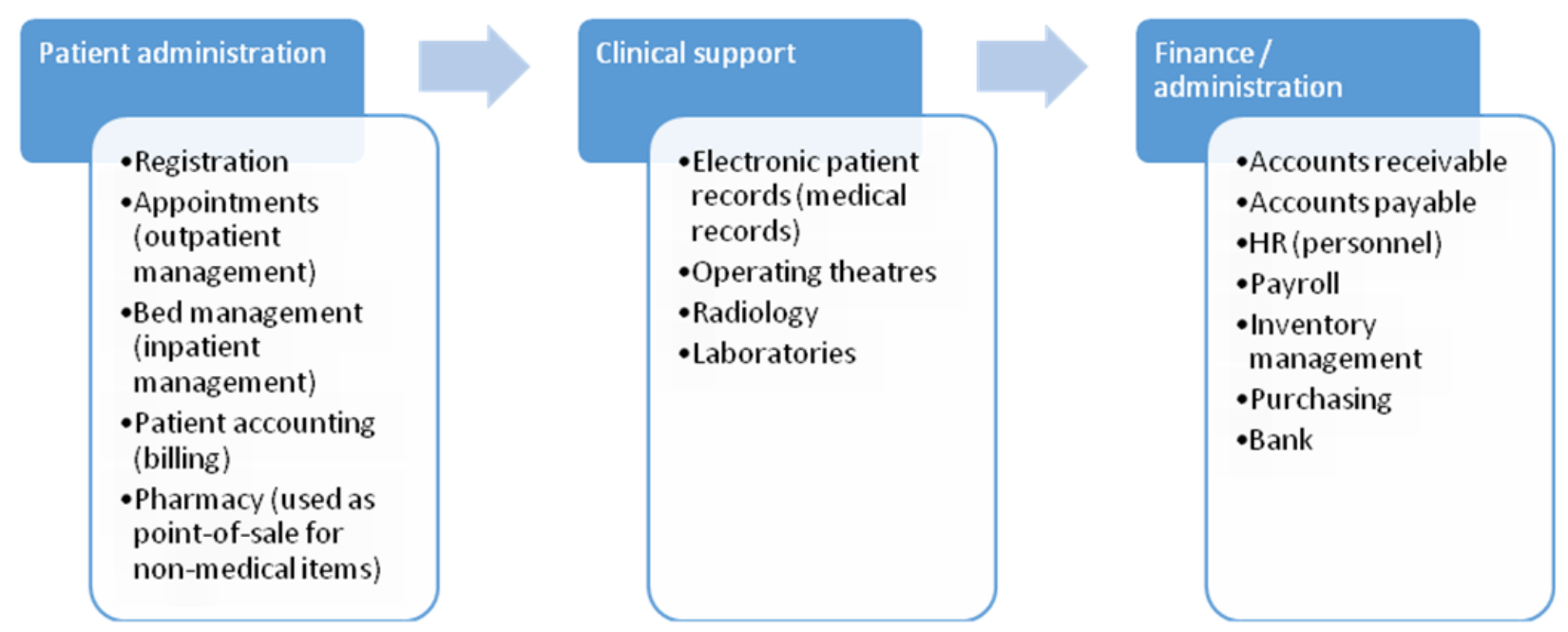

Fig. 4. Basic functional domains studied across various branches 


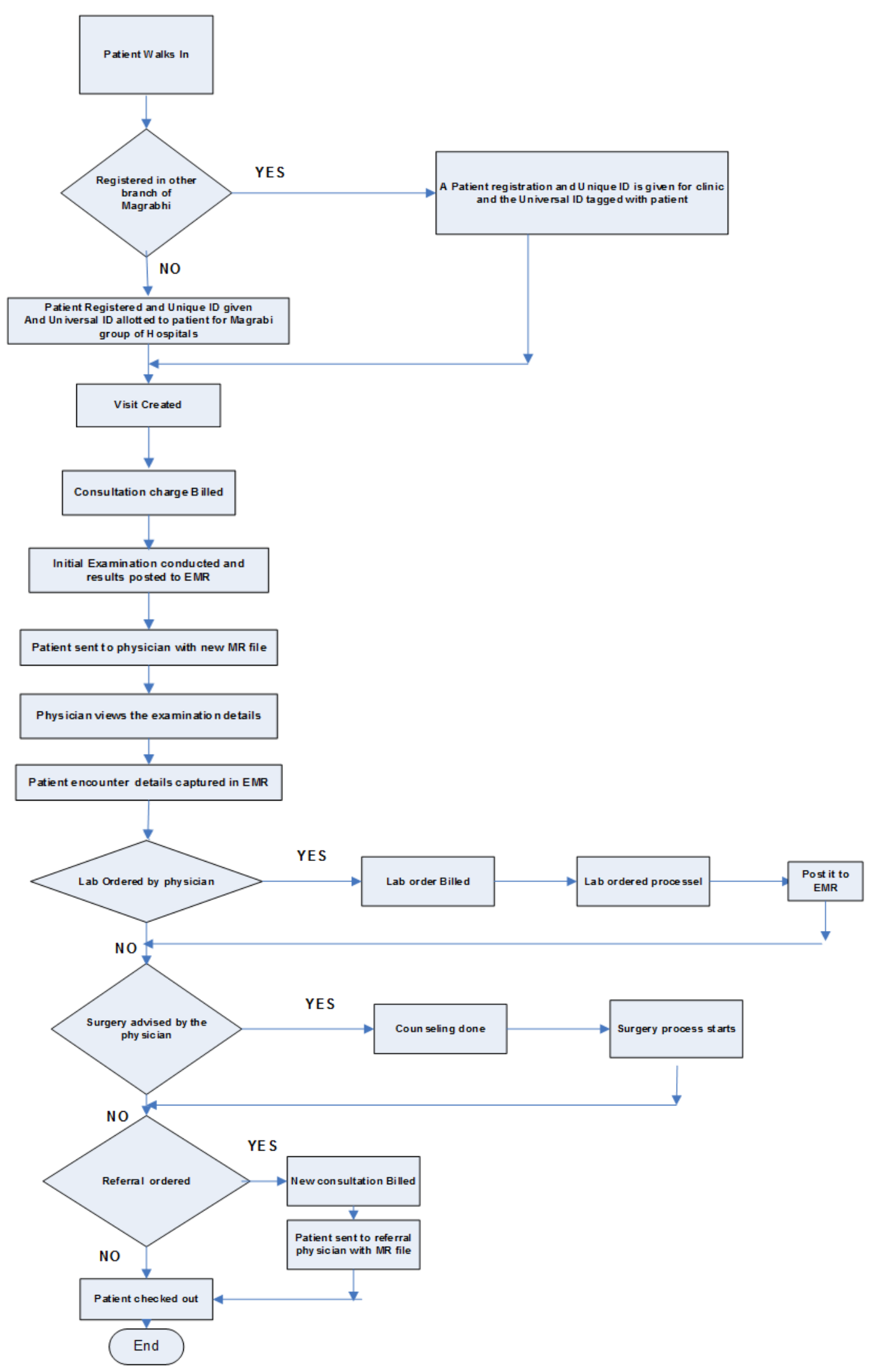

Fig. 5. Flow chart for outpatient service delivery 


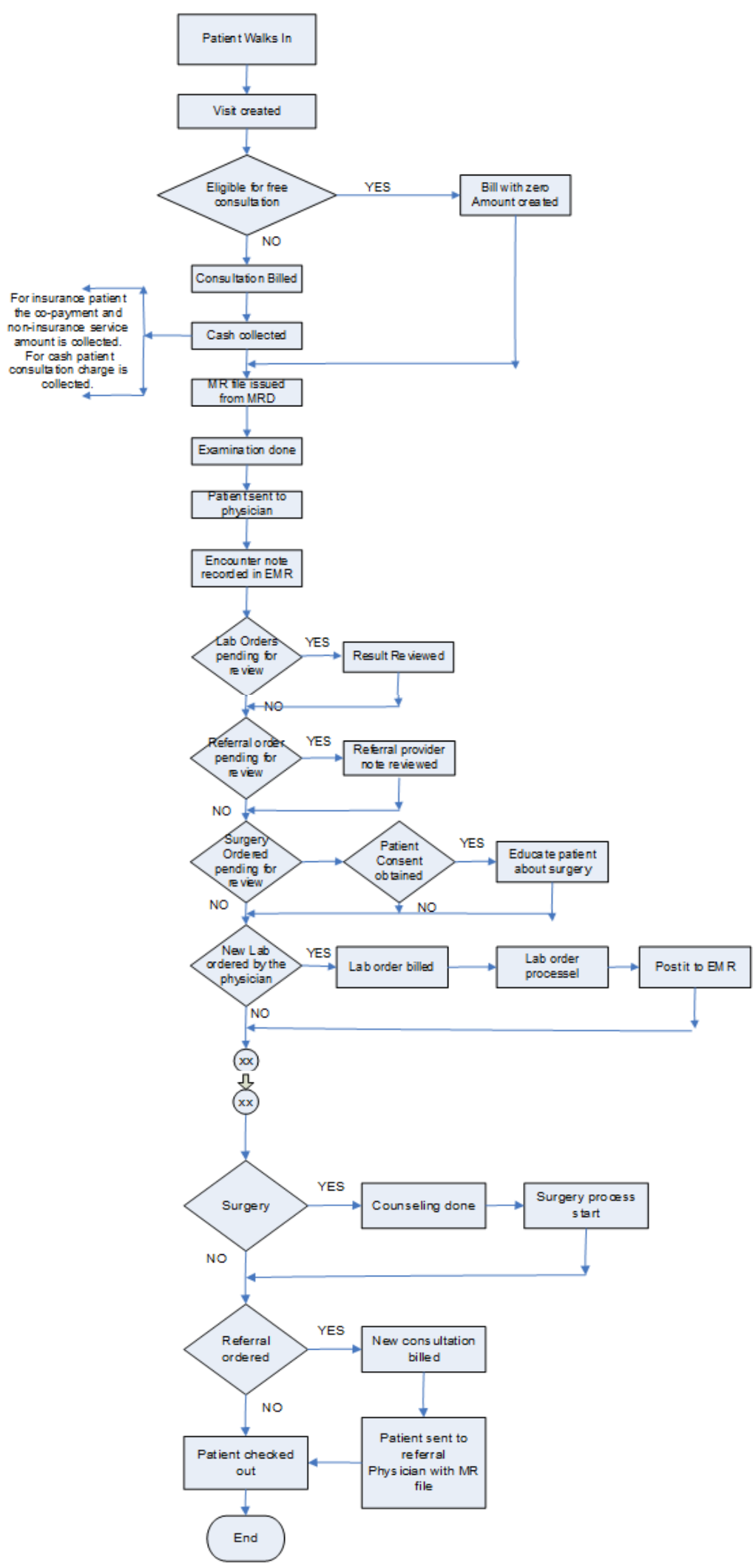

Fig. 6. Flow chart for patient revisit service delivery 


\section{Methodology of Case Study}

Thus, the case study employs a qualitative research methodology to assess the impact of the fully integrated HIS implementation. The selected methodology for conducting this case study is "Business process characterizing modelling", as explained by Yan et al. (2012), to enable the testing of case studies, the analysis of the findings and to provide recommendations and conclusions. A business-process framework that merges theoretical approach with the survey data obtained from the different levels of stakeholders and comparing it to the business process gives the research results credibly. To do so, the business processes (operational, medical, financial and HR) are segregated as per the two cyclesthe revenue cycle and the payment cycle. The latter one is again divided into inventory cycle and payroll cycle. The segregation of the modules of the cycles with respect to various business process is given in the following Table 1.

Categorizing the business processes according the major cycles would enable the identification of the positive impact of having a fully integrated system as well as to identify the gaps in the system's controls. Also, the old manual procedures that are used prior to the implementation of new system can also be understood. Looking into each module as a standalone would not show the bigger picture of the benefits of using such a system because it would be focused on automating the manual process instead of on the applied controls along with the processes from the start point to the end point of each transaction. Thus, the implementation of the project is done in four stagesUnderstanding the sponsor's environment, Data collection phase, Analysis and findings phase, Results evaluation phase and Conclusion phase.

During data collection phase, data pertaining to various business processes is obtained by:

- Interviewing the corporate business development director/corporate financial accounting manager/medical director who supervises the operational business processes

- Reviewing the documents related to the manual process and the system process

- Simulating a random system control check and reviewing the relevant reports

The data collection approaches followed for various cycles (as listed in the above table) are mentioned in the following Table 2 .

Hence, by following these modules, the results of the data collected according to various cycles by different methods are analysed for successful implementation of health information system in the company.
The implementation process has witnessed many changes in the organization vertically and horizontally. It has decreased the burden of some departments and increased the scope of others. One of the change that can be quoted as an example is the integration of HR with the corporate office. This example can site as to how the synchronization of processes is done for achieving the aim of the organization.

\section{Integration with the Corporate Office}

After listing out the status of the system prior and post automation, the new integrated system is linked to the corporate office for grooming centralised operating methodology. Thus, the corporate office HR became an active player for performing these tasks. As this department has transformed from the stage of requesting information from the branches to the stage as main director of the HR that rules and maintains transactions in the group by ensuring the following tasks are performed by the corporate:

\section{Creating a Standardized Setup and Synchronizing it with the Branches}

This enabled the corporate to have a business model for each type of branch according to the services provided by and the size of the facility. The hierarchy will be determined automatically. Of course exceptions are allowed, but at least they are approved by and known to all the concerned people.

\section{Approving the Exceptions}

According to the workflow subsystem, any transaction that exceeds the defined limits in the setup will cause the system to generate a workflow to acquire the approvals needed in a sequence agreed upon by the branch's management and the corporate chiefs.

\section{Monitoring the Monthly KPIs}

By consolidating the reports and performance indicators generated from the system, the corporate will always be able to see the organization direction and to identify problems determine suitable solutions.

By and large, the total process of approaching the issues in a systematic manner in a sequence such as reviewing the sponsor's environment, understanding the data flows, data collection, analysis and findings, evaluation and conclusion landed the Magrabi group in a successful state. Not just the knowledge about process flows, but the information about the individual requirements, capabilities and patient requirements as well as the methodologies adopted made the new technology a good fit for the organization. 
Table 1. Segregation of cycles as per the business process

\section{Cycles}

Payment cycle

$\underline{\text { Business process }}$

Operational

Revenue cycle

Patient registration, Appointment

(scheduling), Bed management,

Point-of-Sale

Medical

Order (Rad/Lab/Pharmacy),

Operation theatre, Patients'

electronic health records

Financial Patient accounting, Accounts

receivable, Bank/Cashier,

General Ledger (GL)

HR

Inventor cycle Payroll cycle

Purchasing, point of sale

Inventory, Fixed assets,

Accounts payable,

Bank/Cashier, GL
Bank/Cashier, GL

HR management module, Payroll module

Table 2. Data collection approaches

\begin{tabular}{ll}
\hline Related business process & Related module \\
\hline Revenue cycle & Patient registration \\
& Appointment \\
& Order (Rad/Lab/Pharmacy) \\
& BED management \\
& Operation theatre \\
& Point of sale \\
& Patient electronic health records \\
& Patient accounting \\
Inventory cycle & Accounts receivable \\
& Bank/Cashier \\
& GL \\
& Purchasing \\
Payroll cycle & Inventory \\
& Fixed assets \\
& Accounts payable \\
& Bank/cashier \\
& Point of sale \\
GL & HR management module \\
& Payroll module \\
\end{tabular}

Table 3. Tabulated form for entering the differences (Manual Vs Automated)

\begin{tabular}{l}
\hline Revenue cycle: \\
Registration \\
Appointment \\
Patient accounting \\
Clinical Support \\
Inpatient management and Bed management \\
Cashier/bank \\
Accounts receivable \\
General Ledger \\
Payment cycle \\
Inventory cycle \\
Fixed assets \\
Items consumed by (resold to) the patients \\
Stationery and low-value office tools \\
The inventory physical count \\
Integration (consolidation) with the corporate \\
Payroll cycle
\end{tabular}


Having understood these workouts, a relative comparison is made in this study to understand as to how the tasks of automation system under each of the processes like registration, appointment etcetera differed from manual entry system. As this case study focused on assessing how a fully integrated information system affected the hospital's state of processes, this comparison would be a ready reckoner for the management. The findings would be tabulated and described according to the business' process modelling as mentioned in the following Table 3.

In addition to the above exercises, the sample of 65 employees who are in managerial cadre are selected at random and their view point about the benefits of the HIS is collected. The rationale behind confining to the mangers for the opinion gathering is their scope of understanding the linkages among the departments and their purview to assess the benefits of the technology at a macro level. The results are given in the following section.

\section{Results}

The following table summarizes the benefits of implementing the fully integrated information system based on the research conducted.

Table 4. Benefits of using a fully integrated healthcare information system

\begin{tabular}{|c|c|}
\hline Dimension & Benefit \\
\hline Process & 1- Controlled the discount process \\
\hline \multirow{12}{*}{ Improvement } & 2- Standardized the business processes \\
\hline & 3- Controlled the medical team's license expiry and renewal \\
\hline & 4- On-time access to the necessary information \\
\hline & 5- Increased the efficiency of inventory handling and management \\
\hline & 6- Increased the efficiency of purchasing by applying bulk purchasing \\
\hline & 7- Controlled cash use and funding \\
\hline & 8- Reduced the time needed to prepare claims \\
\hline & 9- Controlled the insurance companies' contracts \\
\hline & 10- Unified the prices of services provided \\
\hline & 11- Added control to the collection of cash from patients \\
\hline & 12- Reduced the time needed for the registration process \\
\hline & 13- Reduced the time needed to locate a patient's file \\
\hline Decision & 1- Efficient planning \\
\hline \multirow[t]{8}{*}{ Making } & 2- Standardized the information presentation \\
\hline & 3- Standardized the terminology used and the meaning of the information produced within the \\
\hline & different branches of the group \\
\hline & 4- Provides reliable information about the cost of services \\
\hline & 5- Reliable monthly performance indicators for all aspects of the business \\
\hline & 6- Reliable information to produce a business module for each type of facility \\
\hline & 7- Reliable and timely information about the branches' results and performances \\
\hline & 8- Reliable information about the revenue/expenses compared to the budget \\
\hline \multirow[t]{9}{*}{ Financial } & 1- Reduced the gap between the actual expenses and the budgeted expenses \\
\hline & 2- Reduced the cost of employee rotation, as no further training is needed when transferring employees \\
\hline & from one place to another, which eases changes to the structure during the transformation process \\
\hline & 3- Reduced the collection days \\
\hline & 4- Controlled the payment days \\
\hline & 5- Reduced the time needed to generate the monthly/yearly financial results and statements \\
\hline & 6- Reliable financial results recorded in the branches' books \\
\hline & 7- Reduced the inventory cost \\
\hline & 8- Reliable information regarding the customer/vendor balances \\
\hline \multirow[t]{15}{*}{ Operational } & 1- Increased the number of the services provided \\
\hline & 2- Reduced the cancelled appointments \\
\hline & 3- Reduced the patient complains \\
\hline & 4- Better communication with the patients \\
\hline & $\begin{array}{l}\text { 5- Strengthened market competition by increasing the knowledge regarding the cost of services and the pricing boundaries. } \\
6 \text { - Increased the quality of the hired personnel }\end{array}$ \\
\hline & 7- Increased trust in the information presented, especially that presented to external users like auditing firms and the board \\
\hline & 9- Increased the cooperation between the organization's departments by sharing data \\
\hline & 10- Increased the utilization of the available resources (clinic rooms, number of physicians and number of nurses) \\
\hline & 11- Increased the utilization of the facility's buildings by converting the physical patient files to electronic files \\
\hline & 12- Provided reliable statistics about the community’s diseases and created an educational role to \\
\hline & increase the community’s awareness \\
\hline & 13- Reduced the patients' waiting times \\
\hline & 14- Reduced the number of potential surgical patients lost \\
\hline & 15- Increased the quality of the medical services provided \\
\hline & 16- Reduced the medical errors caused by missing files and patient histories \\
\hline
\end{tabular}


As a part of case study, the benefits are compiled from the views of the managers and are categorized according to the following dimensions:

\section{Process Improvement}

The system helped to and had a major impact on transforming the business process in order to improve it.

\section{Decision Making}

This includes the related benefits that had a major influence on the strategic direction of the organization and on the decision-making process.

\section{Financial}

These are the benefits that can be considered to be financial benefit or which caused such improvements to occur.

\section{Operational}

These are the benefits that had a positive impact on operational/managerial performance.

For the sake of better understanding, all the benefits of using a fully integrated healthcare information system in the words of the concerned managers are tabulated (Table 4) below according to process improvement, decision making, financial and operational dimensions.

There are many observations done in this case study to understand the benefits of implementing a health information system at Magrabi Hospitals and Centres.

\section{Conclusion and Recommendations}

By and large, the total process of approaching the issues in a systematic manner in a sequence such as reviewing the sponsor's environment, understanding the data flows, data collection, analysis and findings, evaluation and conclusion landed the Magrabi group in a successful state. The following are the implications of the health system implementation.

\section{Impact of Using a Fully Integrated IT Healthcare System}

Using a fully integrated IT system in healthcare providers' organizations impacts many business aspects positively, starting with the business strategies as it creates new domains and opportunities and includes competitive advantages for the organization by increasing the quality and reducing the operating costs, as well as increasing the staff's skill level. It also has a major impact on the organizational culture and structure, as using IT tools should create a new, cooperative culture within the organization, in addition to creating new types of jobs that require more creative and analytical skills. There will also be an impact on the management, as having access to the information needed changes the way things are managed. Hence, management can focus on strategic tasks instead of controlling all the tasks because the system will take over the controlling part by automating and validating them. Finally, there would be a complete change in the work environment as a result of enabling the rearrangement of the work place and creating new types of employees and staff members. The synchronized system will also provides the possibility of working with virtual teams and working from outside the organization.

\section{Managerial Implications}

The successful use of the fully integrated healthcare IT system and the impact thereof will have implications at all levels. The research results reveal that the level most affected is the managerial level, as the strategic decisions taken in day to day issues as well as long term issues highly influence the organization. Other implications include aligning IT with the business strategies, without which integrating IT as a tool within the business' needs would be very difficult to achieve the strategic business goals. Another implication is, understanding the changes that occurred as a result of using such IT systems in order to enable continuous improvements in the work processes and the environment. Also, to accommodate the expansion of the wider work place via virtual teams, which leads to structural changes by removing the limitations of hierarchy, thus creating further challenges for the managers regarding the management of new forms of teams and employees. The IT system should be customizable to accommodate the new changes that will be needed in due course of time, as the changes are continuous in order to keep improving.

\section{Lessons Learned}

Adopting a fully integrated healthcare system involves more than selecting and implementing an IT system. It requires a complete organizational transformation that is affected by the quality of the users of the system and their ability to use the available systems. This paper has shown that organizational transformation combined with the adoption of a fully integrated healthcare system improves overall organizational performance depending on the availability of the information. That is, without having the entire scope of the transformation, the information system alone can not be able to provide the intended goals. This is the main reason why most of the healthcare information system implementations fail in Saudi Arabia. Although Saudi Arabia uses the same systems that succeeded in the developed countries, as Saudi Arabia treats them as standalone projects, the results are not as per the expectations. This limitation can be encountered by integrating the systems according to the following aspects: 
- System module cross-functional integration

- Implementation integration with organizational transformation; this transformation should include changes to the business processes, organizational culture and people

After satisfying these integration aspects, the benefits of investing in a fully integrated healthcare system will be obvious.

\section{Acknowledgment}

Thanks to management and staff of Magribi Hospital to collect the data from their organization for this research project.

\section{Author's Contributions:}

Diaa Eldin ELSaied: Methodology, Data Collection, Analysis.

Habib Ullah Khan: Introduction Analysis and Discussion, Conclusion.

\section{Ethics}

Due to strong support of management in Magrabi hospital no ethical issues raised during whole research process. Collected data was saved on a local hard drive with Lead research author and never shared with any other party.

\section{References}

Abraham, C. and I. Junglas, 2011. From cacophony to harmony: A case study about the IS implementation process as an opportunity for organizational transformation at sentara healthcare. J. Strategic Inform. Syst., 20: 177-197.

DOI: $10.1016 /$ j.jsis.2011.03.005

Abukhader, S., 2015. ERP implementation in the private hospitals of Saudi Arabia. Int. J. Healthcare Manage., 8: 77-88. DOI: 10.1179/2047971914Y.0000000092

Alasmary, M., A. El Metwally and M. Househ, 2014. The association between computer literacy and training on clinical productivity and user satisfaction in using the electronic medical record in Saudi Arabia. J. Med. Syst., 38: 69-69.

DOI: $10.1007 / \mathrm{s} 10916-014-0069-2$

Al-Dosari, B., 2012. User acceptance of a Picture Archiving and Communication System (PACS) in a Saudi Arabian hospital radiology department. BMC Med. Inform. Decis. Mak., 12: 44-44.

DOI: $10.1186 / 1472-6947-12-44$

Al-Gharbi, K., A. Al-Badi, S. Gattoufi and A. AlHashmi, 2015. Al-Shifa healthcare information system in Oman: A debatable implementation success. EJISDC, 66: 1-17.
Ali, M.S., 2013. Improve of health care systems for smart hospitals based on UML and semantic web technology. Greener J. Internet Inform. Commun. Syst., 1: 044-054.

Alkraiji, A., T. Jackson and I. Murray, 2013. Barriers to the widespread adoption of health data standards: An exploratory qualitative study in tertiary healthcare organizations in Saudi Arabia. J. Med. Syst., 37: 9895-9895. DOI: $10.1007 / \mathrm{s} 10916-012-9895-2$

Almalki, M., G. Fitzgerald and M. Clark, 2011. Health care system in Saudi Arabia: An overview. Eastern Mediterr. Health J., 17: 784-793. PMID: 22256414

Alshami, M., S. Almutairi and M. Househ, 2014. The implementation experience of an electronic referral system in Saudi Arabia: A case study. Stud. Health Technol. Inform., 202: 138-141. PMID: 25000035

Al-Sharqi, O.Z. and M.T. Abdullah, 2013. "Diagnosing" Saudi health reforms: is NHIS the right "prescription"? Int. J. Health Plann. Manage., 28: 308-319. DOI: $10.1002 / \mathrm{hpm} .2148$

Anwar, F., A. Shamim and S. Khan, 2011. Barriers in adoption of health information technology in developing societies. Int. J. Adv. Comput. Sci. Applic., 2: 40-45. DOI: 10.14569/IJACSA.2011.020808

Askoul, R., H.U. Khan and V.V. Madhavi Lalitha, 2016. Cross-functional integration of marketing and information services in banking: A cross-industry comparison. Int. J. Process Manage. Benchmark., 6: 57-78. DOI: 10.1504/IJPMB.2016.073326

Awan, M.A. and H.U. Khan, 2016. Status of internet addiction among college students: A case of South Korea. Proceedings of the 1st American Academic Research Conference on Global Business, Economics, Finance and Social Sciences, May 25-28, New York, USA.

Awan, M.A., H.U. Khan and W. Zhang, 2012. A comparative study on online service quality perception of two major regional economies. Int. J. e-Educ. e-Bus. e-Manage. e-Learn., 2: 529-551.

Awan, M.A., H.U. Khan and H.C. Ho, 2016. Online banking: A comparative study of Chinese and Saudi customers perceptions of service quality. J. Internet Bank. Commerce, 21: 529-533. DOI: 10.7763/IJEEEE.2012.V2.178

Aziz, N.F.A. and N.A. Mohamadali, 2015. The challenges of human factors for implementation of information systems in the healthcare. ARPN J. Eng. Applied Sci., 10: 17914-17922.

Bankole, O.A., M. Lalitha, H.U. Khan and A. Jinugu, 2017. Information technology in the maritime industry past, present and future: Focus on LNG carriers. Proceedings of the 7th IEEE International Advance Computing Conference, Jan. 5-7, Hyderabad, India. 
Bashir, G.M. and H.U. Khan, 2016. Factors affecting learning capacity of information technology concepts in a classroom environment of adult learner. Proceedings of the 15th International Conference on Information Technology Based Higher Education and Training, Sept. 8-10, IEEE Xplore Press, Istanbul, Turkey, pp: 1-6. DOI: 10.1109/ITHET.2016.7760729

Bashir, G.M., H.U. Khan, S.D. Fournier-Bonilla, 2016. Applying andragogy theory to an adult multicultural audience: How cultural factors influence the capacity for adults to learn information technology concepts in a classroom environment. Proceedings of the Northeast Decision Sciences Institute Conference, Mar. 31-Apr. 2, Alexandria, Virginia, USA.

Brock, V.F. and H.U. Khan, 2017. Are enterprises ready for big data analytics? A survey-based approach. Int. J. Bus. Inform. Syst., 25: 256-277.

Clementking, A. and A. Muhammad, 2013. Technology based learning analysis of CBCS model at KKU. Int. J. Emerg. Technol. Learn., 8: 8-12. DOI: $10.3991 /$ ijet.v8i3.2617

Das, A. and H.U. Khan, 2016. Security behaviors of smartphone users. Inform. Comput. Security, 24: 116-134. DOI: 10.1108/ICS-04-2015-0018

Ejike, A.C., H.U. Khan and S.D. Fournier-Bonilla, 2016. Possible impact of mobile banking on traditional banking: A case study of Nigeria. Proceedings of the Northeast Decision Sciences Institute Conference, Mar. 31-Apr. 2, Alexandria, Virginia, USA.

Fichman, R., R. Kohli and R. Krishnan, 2011. The Role of Information Systems in Healthcare: Current Research and Future Trends. Inform. Syst. Res., 22: 419-428. DOI: $10.1287 /$ isre. 1110.0382

Grönevall, R. and M. Danilovic, 2014. Designing an integrated project, program and portfolio system: A case study of healthcare. Proceedings of the 16th International DSM Conference, Jul. 2-4, Paris, France, pp: 309-318.

DOI: $10.3139 / 9781569904923.030$

Halabi, A.E., A. Hachem, L. Al-Akhrass, H. Artail and H.U. Khan, 2014. Identifying the linkability between Web servers for enhanced internet computing. Proceedings of the 17th IEEE Mediterranean Electrotechnical Conference, Apr. 13-16, IEEE Xplore Press, Beirut, Lebanon, pp: 1-5. DOI: 10.1109/MELCON.2014.6820521

Hasanain, R., K. Vallmuur and M. Clark, 2015. Electronic medical record systems in Saudi Arabia: Knowledge and preferences of healthcare professionals. J. Health Inform. Dev. Countries, 9: 23-31.
Hassan, I.M., H.U. Khan and M. Lalitha, 2016. Pedagogical potentials of IEEE 802.11 WLAN to Nigerian Universities: A case study of the University of Uyo. Int. J. Inform. Educ. Technol., 6: 256-261. DOI: 10.7763/IJIET.2016.V6.696

Hassan, I.M., H.U. Khan, R. Zaitun and G. Mardini, 2015. Pedagogical potentials of IEEE 802.11 WLAN to Higher Educational Institutions: A case study of Nigerian based University. Proceedings of the IEEE 9th International Conference on Semantic Computing, Feb. 7-9, IEEE Xplore Press, Anhaim, USA, pp: 165-166.

DOI: $10.1109 /$ ICOSC.2015.7050799

Hayajneh, S. and A.A. Zaghloul, 2012. Barriers to the adoption of health information technology in Arab countries' hospitals: Practitioners' perspective. Proceedings of the 24th International Conference of the European Federation for Medical Informatics Quality of Life through Quality of Information, (LQI' 12).

Heang, J.F. and H.U. Khan, 2015. The role of internet marketing in the development of agricultural industry: A case study of China. J. Internet Commerce, 14: 1-49. DOI: $10.1080 / 15332861.2015 .1011569$

Ho, H.C., M.A. Awan and H.U. Khan, 2016. Luxury brands and corporate social responsibility: A perspective on consumers' preferences. J. Int. Manage. Stud., 16: 77-81. DOI: 10.18374/JIMS-16-1.9

Hung, S., C. Chen and K. Wang, 2014. Critical success factors for the implementation of integrated healthcare information systems projects: An organizational fit perspective. Commun. Assoc. Inform. Syst., 34: 775-796.

Khalifa, M., 2013. Barriers to health information systems and electronic medical records implementation. A field study of Saudi Arabian hospitals. Proc. Comput. Sci., 21: 335-342. DOI: $10.1016 /$ j.procs.2013.09.044

Khalifa, M., 2014. Technical and human challenges of implementing hospital information systems in Saudi Arabia. J. Health Inform. Dev. Countries, 8: 12-25.

Khan, H.U. and A. Alhusseini, 2015. Optimized web design in the Saudi Culture. Proceedings of the IEEE Science and Information Conference, Jul. 28-30, IEEE Xplore Press, London, UK, pp: 906-915. DOI: $10.1109 /$ SAI.2015.7237250

Khan, H.U. and A.C. Ejike, 2017. An assessment of the impact of mobile banking on traditional banking in Nigeria. Int. J. Bus. Excellence, 11: 446-463. DOI: $10.1504 / \mathrm{IJBEX} .2017 .082573$

Khan, H.U. and O.A. Adediji, 2017. Need for RADAR system utilisation for maritime traffic management: A case of Congo River Basin. Int. J. Comput. Syst. Eng. 
Khan, H.U. and S.D. Fournier-Bonilla, 2016. Technological infrastructure effects on export diversification: A case study of Qatar. Proceedings of the Northeast Decision Sciences Institute Conference, Mar. 31-Apr. 2, Alexandria, Virginia, USA.

Khan, H.U., 2012. Computer mediated communication, quality of learning and performance. J. GSTF Bus. Rev., 1: 81-88.

Khan, H.U., 2013a. Use of e-learning tools to solve group work problems in higher education: A case study of gulf countries. Adv. Comput. Sci.: Int. J., 2: 90-96.

Khan, H.U., 2013b. Role of computer mediated communication in affect empowerment and performance improvement. IFRSA's Int. J. Comput., 3: $165-171$.

Khan, H.U., 2016. Possible effect of video lecture capture technology on the cognitive Empowerment of higher education students: A case study of gulfbased university. Int. J. Innovat. Learn., 20: 68-84. DOI: $10.1504 /$ ijil.2016.076672

Khan, H.U. and M.A. Awan, 2017. Possible factors affecting internet addiction: A case study of higher education students of Qatar. Int. J. Bus. Inform. Syst.

Khan, H.U. and S. Uwemi, 2017. Possible impact Of Ecommerce strategies on the utilization of $\mathrm{e}-$ commerce in Nigeria. Int. J. Bus. Innovat. Res.

Khan, H.U., H. Artail, Z. Malik and M. Niazi, 2014a. Information technology adoption, possible challenges and framework of supply chain management: A case study of a leading gulf economy. Proceedings of the 4th International Conference on Engineering Technology and Technopreneurship, Aug. 27-29, IEEE Xplore Press, Kuala Lumpur, Malaysia, pp: 1-5. DOI: 10.1109/ICE2T.2014.7006207

Khan, H.U., J.F. Omonaiye and V.V. Madhavi Lalitha, 2017a. Employees' perception as internal customers about online services: A case study of banking sector in Nigeria. Int. J. Bus. Innovat. Res., 13: 181-202. DOI: 10.1504/IJBIR.2017.083540

Khan, H.U., M.A. Awan and H.C. Ho, 2014b. How do Chinese and Saudi customers perceive online service quality? A comparative study. J. Bus. Inquiry, 13: 142-157.

Khan, H.U., O.A. Bankole and M.K. Alomari, 2017 b. Possible effect of IT introduction into the election process: A case study of Nigeria. Int. J. Bus. Forecast. Market. Intell., 3: 109-129. DOI: 10.1504/IJBFMI.2017.084046

Khan, H.U., S. Ahmed and M. Abdollahian, 2013. Supply chain technology acceptance, adoption and possible challenges: A case study of service organizations of Saudi Arabia. Proceedings of the 10th International Conference on Information Technology: New Generations, Apr. 15-17, IEEE Xplore Press, Las Vegas, Nevada, USA, pp: 590- 95. DOI: 10.1109/ITNG.2013.75
Khan, H.U., S.D. Fournier-Bonilla, A. Jinugu and V.V. Madhavi Lalitha, 2016. Possible challenges of the successful implementation of CRM in the service sector: A case study of Saudi Arabia. Proceedings of the Northeast Decision Sciences Institute Conference, Mar. 31-Apr 2, Alexandria, Virginia, USA.

Melin, U. and K. Axelsson, 2014. Implementing healthcare information systems: Mirroring a wide spectrum of images of an IT project. Health Policy Technol., 3: 26-35. DOI: 10.1016/j.hlpt.2013.11.001

Musa, A., H.U. Khan and K. Alshare, 2015. Factors influence consumers' adoption of mobile payment devices in Qatar. Int. J. Mobile Commun., 13: 670-689. DOI: 10.1504/IJMC.2015.072100

Najmi, E., K. Hashmi, Z. Malik, A. Rezgui and H.U. Khan, 2015. CAPRA: A comprehensive approach to product ranking using customer reviews. Computing, 97: 843-867. DOI: 10.1007/s00607-015-0439-8

Omonaiye, J.F., V.V. Madhavi Lalitha, H.U. Khan, R. Signh and S.D. Fournier-Bonilla, 2015. Ability and hurdle to provide Banking online services: A case study of banking employees in Nigeria. Proceedings of the IEEE 2nd International Conference on Cyber Security and Cloud Computing, Nov. 3-5, IEEE Xplore Press, New York, pp: 482-487.

DOI: 10.1109/CSCloud.2015.48

Schalkwijk, A.A.H., G. Nijpels, S.D.M. Bot and P.J.M. Elders, 2016. Health care providers' perceived barriers to and need for the implementation of a national integrated health care standard on childhood obesity in the Netherlands-a mixed methods approach. BMC Health Services Res., 16: 83-38. DOI: 10.1186/s12913-016-1324-7

Silver, M.S., M.L. Markus and C.M. Beath, 1995. The information technology interaction model: A foundation for the MBA core course. MIS Q., 19: 361-390. DOI: $10.2307 / 249600$

Smuts, R.G., M. Lalitha and H.U. Khan, 2017. Change management guidelines that address barriers to technology adoption in an HEI context. Proceedings of the 7th IEEE International Advance Computing Conference, Jan. 5-7, Hyderabad, India.

Uwemi, S. and H.U. Khan, 2016. E-commerce, challenges and developing countries. Proceedings of the DSI Annual Meeting in Austin, Nov. 19-22, TX, USA.

Uwemi, S., H.U. Khan and S.D. Fournier-Bonilla, 2016. Challenges of e-commerce in developing countries: Nigeria as case study. Proceedings of the Northeast Decision Sciences Institute Conference, Mar. 31-Apr. 2, Alexandria, Virginia, USA.

Yan, Z., R. Dijkman and P. Grefen, 2012. Business process model repositories-framework and survey. Inform. Software Technol., 54: 380-395. DOI: 10.1016/j.infsof.2011.11.005 